\title{
Identification of Fungal rDNA Associated with Soil Suppressiveness Against Heterodera schachtii Using Oligonucleotide Fingerprinting
}

\author{
Bei Yin, Lea Valinsky, Xuebiao Gao, J. Ole Becker, and James Borneman
}

First, second, and fifth authors: Department of Plant Pathology, University of California, Riverside 92521; and third and forth authors: Department of Nematology, University of California, Riverside 92521.

Accepted for publication 18 March 2003.

\section{ABSTRACT}

Yin, B., Valinsky, L., Gao, X., Becker, J. O., and Borneman, J. 2003. Identification of fungal rDNA associated with soil suppressiveness against Heterodera schachtii using oligonucleotide fingerprinting. Phytopathology 93:1006-1013.

To understand the nature of a soil with suppressiveness against Heterodera schachtii, an rDNA analysis was used to identify fungi associated with $H$. schachtii cysts obtained from soils possessing various levels of suppressiveness. Because $H$. schachtii cysts isolated from these suppressive soils can transfer this beneficial property to nonsuppressive soils, analysis of the microorganisms associated with the cysts should lead to the identification of the causal organisms. Five soil treatments, generated by mixing different amounts of suppressive and fumigation-induced nonsuppressive soils, were infested with second-stage juveniles of $H$. schachtii and cropped with mustard-greens. Fungi were identified through an rDNA analysis termed oligonucleotide fingerprinting of ribosomal RNA genes (OFRG). Cysts obtained from soil mixtures consisting of 10 and $100 \%$ suppressive soil predominantly contained fungal rDNA with high sequence identity to Dactylella oviparasitica. The dominant fungal rDNA in the cysts isolated from the soil mixtures composed of 0.1 and $1 \%$ suppressive soil had high sequence identity to Fusarium oxysporum. Polymerase chain reaction (PCR) amplifications performed with sequence-selective primers corroborated the treatment-specific distribution of rDNA clones obtained by the OFRG analysis. When these sequence-selective PCR primers were used to examine $H$. schachtii cysts from biocidal soil treatments that produced various levels of suppressiveness, only the $D$. oviparasitica-like rDNA was consistently identified in the highly suppressive soils.
Pest and disease suppressive soils provide unique opportunities for pest management research. For biological control, they represent a source of beneficial microorganisms (8). In this approach, organisms isolated from suppressive soils can be analyzed to determine their ability to parasitize, antagonize, or otherwise inhibit the pest. Because most attempts at managing soilborne pests through the application of biocontrol agents have not produced sufficient or consistent results, new approaches are needed. One strategy for increasing the efficacy of biocontrol research may come from a greater understanding of how suppressive soils inhibit pests and disease. A review by Weller et al. (36) describes several systems where a greater understanding of suppressiveness was obtained through the identification of microorganisms associated with these phenomena.

One of the challenges associated with understanding suppressive soils stems from the immense diversity of microorganisms that inhabit these ecosystems. Estimates suggest that 4,000 to 40,000 bacterial species can inhabit a single gram of soil $(29,30)$. For fungi, projections suggest there are 1.5 million extant species, many of which inhabit soil $(6,12)$. Another difficulty with microbial community studies comes from the limitations associated with the experimental methods. Traditional methods include isolation on culture media followed by characterization using morphological and physiological traits. However, because many microorganisms do not readily grow on laboratory media, this approach has significant limitations $(2,6,35)$. The development of strategies to analyze ribosomal RNA genes (rDNA) obtained from the environment has provided a means for identifying microorganisms with-

Corresponding author: J. Borneman; E-mail address: borneman@ucrac1.ucr.edu

Publication no. P-2003-0528-01R

(c) 2003 The American Phytopathological Society out this culture bias and has led to the identification of thousands of previously undescribed phylotypes $(3,10,11,21,22,34)$.

Several approaches for analyzing rDNA have been devised. The most common methods include denaturing gradient gel electrophoresis (19) and terminal restriction fragment length polymorphism (18), both of which allow many samples to be analyzed in a relatively short time period. One problem with these approaches is their limited resolution, as communities that may contain thousands of different species are grouped into a relatively small number of bands or peaks. More detailed depictions of community composition can be obtained by extensive sequence analysis of rDNA clone libraries. However, this approach is not commonly practiced because of the high costs associated with examining such diverse communities.

To address these limitations, we developed a new array-based approach termed oligonucleotide fingerprinting of ribosomal RNA genes (OFRG) (32,33). OFRG permits extensive analysis of microbial community composition by sorting rDNA clones into taxonomic clusters. Clone libraries are constructed using polymerase chain reaction (PCR) primers designed to selectively amplify rRNA genes from DNA isolated from environmental samples. The cloned rDNA fragments are arrayed on nylon membranes and then subjected to a series of hybridization experiments, each using a single DNA probe. For every hybridization experiment, the signal intensities are transformed into three discrete values, 0,1 , and $\mathrm{N}$, where 0 and 1 specify negative and positive hybridization events, respectively, and $\mathrm{N}$ designates an uncertain assignment. This process creates a hybridization fingerprint for each clone. The clones are identified by clustering their hybridization fingerprints with those of known sequences or by nucleotide sequence analysis of representative clones distributed throughout the tree.

In this project, we used OFRG to identify fungal rDNA associated with a soil with suppressiveness against the plant-parasitic nematode Heterodera schachtii. The suppressive soil is located in 
field $9 \mathrm{E}$ at the University of California-Riverside Agricultural Research Station. This soil contains a low population density of the beet cyst nematode that does not significantly increase despite cropping to a susceptible host and conducive environmental conditions (37). The suppressiveness has a biological origin, as fumigation with various broad-spectrum chemicals (methyl bromide, methyl iodide, and metam sodium) and exposure to aerated steam reduced suppressiveness to undetectable levels (37). Suppressiveness was transferred to a fumigated field site with $1 \% 9 \mathrm{E}$ soil and in greenhouse trials with only $0.1 \%$ (38). In contrast to most documented soil transfer cases, which have usually taken two or more growing seasons (8), the suppressiveness in this system was established within one growing season. Perhaps the most interesting discovery thus far is that the suppressive nature of the soil can be transferred via nematode cysts that developed in the $9 \mathrm{E}$ field soil (39). This crucial feature should greatly assist investigations directed toward the identification of the organisms involved in the suppressiveness, because the microbial communities associated with the cysts are likely to be much less complex than that of the soil.

The experimental approach used in this study involved identifying fungal rDNA from nematode cysts obtained from soil mixtures possessing various degrees of $H$. schachtii suppressiveness. We postulated that we could determine which fungi were involved in the suppressiveness by identifying species whose population levels positively correlated with the suppressiveness. The experimental plan had three phases. The first phase was to identify fungal rDNA from cysts that developed in soils possessing various degrees of suppressiveness generated by mixing different amounts of suppressive and fumigation-induced nonsuppressive soil. rDNA sequences that were more abundant in cysts from the highly suppressive soils than in cysts from the less suppressive soils were considered candidate sequences. The second phase of this experimental plan was to verify the results obtained from phase one. For this work, we designed selective PCR primers for each of the candidate rDNA sequences. These primers were used to determine the relative amounts of the candidate sequences in cysts from soils possessing various levels of suppressiveness produced by three different methods: (i) mixing different quantities of suppressive and fumigation-induced nonsuppressive soil, (ii) using three biocidal treatments of the suppressive soil, and (iii) transferring cysts to a nonsuppressive soil. In phase three, we used quantitative PCR analysis to confirm the correlations between the amounts of rDNA and the $H$. schachtii suppressiveness. The rationale for using three different greenhouse experiments instead of repeating one type of trial was that any single greenhouse experiment might lead to the identification of organisms whose population levels correlate with suppressiveness but which exhibit this trend for reasons unrelated to the suppressiveness. Overall, this experimental approach provided replication and independent validation by examining $H$. schachtii cysts from three complimentary greenhouse experiments using two different rDNA-based approaches.

A parallel study was performed to examine the bacterial rDNA associated with the $H$. schachtii suppressiveness (41). This work identified one group of bacterial clones with high sequence identity to rDNA from several Rhizobium spp. and uncultured $\alpha$ proteobacterial clones that positively correlated with the $H$. schachtii suppressiveness.

\section{MATERIALS AND METHODS}

Fungal strain. Dactylella oviparasitica was obtained from the University of California-Riverside Culture Collection of Nematode-Destroying Fungi by J. O. Becker.

Greenhouse trial with five 9E soil mixtures. $H$. schachtii suppressive soil was collected from the upper $10 \mathrm{~cm}$ from field $9 \mathrm{E}$ at the University of California-Riverside Agricultural Research Station. The 9E soil was a Hanford fine sandy loam (60.9\% sand,
$29.6 \%$ silt, and $9.5 \%$ clay, $\mathrm{pH}$ 8) (39). The H. schachtii suppressiveness developed at the $9 \mathrm{E}$ site after several years of continuous cropping to hosts of the nematode (37). After removing the large aggregates using a sieve with 6-mm openings, one part of the soil was fumigated with $2 \mathrm{ml}$ of methyl iodide $(690 \mathrm{~kg} / \mathrm{ha})$ for 4 days in 19-liter polyethylene buckets (4). Three days after fumigation, all fumigated and untreated soils were mixed 10:1 with silica sand. Soil mixtures were then made by amending fumigated $9 \mathrm{E}$ soil with $0.1,1.0$, and $10 \%$ (dry, wt/wt) nonfumigated 9E soil. Nonfumigated and fumigated $9 \mathrm{E}$ soil served as the suppressive and nonsuppressive controls, respectively. Soils were placed in 6-in. $(15.24-\mathrm{cm})$ pots and sown with five seeds of mustard-greens, Brassica juncea cv. Florida broadleaf (Lockhart Seeds, Stockton, $\mathrm{CA})$. All pots were placed in a greenhouse under natural light at $23 \pm 3^{\circ} \mathrm{C}$ in a randomized complete block design with five replicates. Plants were watered with tap water. After emergence, the seedlings were thinned to one per pot and fertilized with $6 \mathrm{~g}$ of slow-release fertilizer (Sierra 17-6-10 plus Minors, Scotts-Sierra Horticultural Products Co., Marysville, OH). Four weeks after seeding, each pot was inoculated with 10,000 second-stage juveniles of $H$. schachtii. Juveniles were collected and enumerated using a zinc chloride hatching protocol as described previously (23). Starting 3 weeks after inoculation, each plant was fertilized with $50 \mathrm{ml}$ of a nutrient solution (Miracle Gro 15-30-15, Scotts Miracle-Gro Products, Marysville, $\mathrm{OH}$ ) every 2 weeks. Eleven weeks after inoculation, plant tops were cut off at soil level and weighed after oven-drying at $80^{\circ} \mathrm{C}$ for 2 days. Soil with the root system was collected and placed in a container. Roots were cut into pieces $(\approx 0.5 \mathrm{~cm})$ and mixed thoroughly with soil. Two $350-\mathrm{g}$ subsamples of this soil mixture were collected for cyst extraction using a modified Fenwick flotation can method (7). Cysts were counted and then broken in a tissue homogenizer for egg counting. Two hundred grams of the soil mixture was collected, sieved using a screen with $1.0-\mathrm{mm}$ openings, and stored at $-20^{\circ} \mathrm{C}$ for fungal rDNA analysis.

Transfer of suppressiveness with $\boldsymbol{H}$. schachtii cysts. The procedures for this trial were similar to those described previously (39). Cycle 1-suppressive 9E soil was collected, screened, portions fumigated, and mixed with sand as described previously. The fumigated and nonfumigated 9E soils were placed in root observation chambers (height by width by depth, 26 by 23 by $3.8 \mathrm{~cm}$, respectively), five replicates for each soil treatment. One side of the root observation chamber was constructed of clear plastic and the other of black plastic. Soils were sown with 15 seeds of $B$. juncea. The chambers were placed in a greenhouse under natural light at $23 \pm 3^{\circ} \mathrm{C}$ in a randomized complete block design with the translucent side of the chambers facing downward at a $45^{\circ}$ angle. Plants were watered with tap water. After emergence, the seedlings were thinned to five per chamber, and the plants were fertilized with $6 \mathrm{~g}$ of slow-release fertilizer (Sierra 17-6-10 plus Minors, Scotts-Sierra Horticultural Products Co.). Four weeks after seeding, each chamber was inoculated with 15,000 secondstage juveniles of $H$. schachtii. Ten weeks after inoculation, the chambers were opened and the cysts were manually collected from the roots. Cysts from the five replicates were pooled. A portion of these cysts were saved for fungal rDNA analysis, and the rest were used for the next cycle of this experiment. Cycle 2 fumigated 9E soil was mixed 1:1 with silica sand containing $H$. schachtii cysts that were established after two nematode generations in the greenhouse. Styrofoam cups $(350 \mathrm{ml})$ were filled with $360 \mathrm{~g}$ (wet weight) of this soil mixture, which contained approximately 133 cysts $(51,120 \mathrm{H}$. schachtii eggs). Five treatments were examined. To each cup, we added either (i) three cysts from the suppressive soil treatment from cycle 1; (ii) three cysts from the nonsuppressive soil treatment from cycle 1; (iii) three cysts from the suppressive soil treatment from cycle 1 that were treated with $10 \%$ bleach for 1 min and washed six times with sterile $\mathrm{H}_{2} \mathrm{O}$; (iv) $5 \mathrm{~g}$ of suppressive 9E soil (positive control); or (v) no amendment 
(negative control). All cups were placed in a greenhouse under natural light at $23 \pm 3^{\circ} \mathrm{C}$ in a randomized complete block design with five replicates. Cups were watered as needed with tap water. One month later, the soil in each cup was mixed thoroughly in a plastic bag, and $350 \mathrm{~g}$ was placed back into the cup. Five seeds of $B$. juncea were sown in each cup. Plants were thinned to one per cup after emergence and fertilized with $3 \mathrm{~g}$ of slow-release fertilizer (Sierra 17-6-10 plus Minors, Scotts-Sierra Horticultural Products Co.). Twelve weeks after planting, plants were harvested, and cysts and eggs were extracted and counted as described in the previous section.

Biocidal treatments of $9 E$ soil. Suppressive 9E soil was collected, screened, portions fumigated, and mixed with sand as described previously. This greenhouse trial had four treatments: (i) fludioxonil (Syngenta, Greensboro, NC), (ii) formaldehyde, (iii) methyl iodide, and (iv) untreated suppressive 9E soil. Each treatment had six replicates. For the fludioxonil treatment, $240 \mathrm{ml}$ of a suspension containing fludioxonil $(100 \mathrm{mg} / \mathrm{liter})$ was added to 15-cm pulp pots filled with $2,000 \mathrm{~cm}^{3}$ of soil and incubated at room temperature for 7 days. For the formaldehyde treatment, $5.47 \mathrm{ml}$ of formaldehyde $(37 \%)$ was added to $15-\mathrm{cm}$ pulp pots filled with $2,000 \mathrm{~cm}^{3}$ of soil and incubated at room temperature for 2 weeks. The methyl iodide treatment was done as described previously (4). After completing the biocidal treatments, the soils were mixed separately in polyethylene bags $(50$ by $45 \mathrm{~cm}$ ) and repotted. Four seeds of Swiss chard, Beta vulgaris (cv. Large White Ribbed, Lockard Seeds, Stockton, CA) were sown in each pot. Each pot also received $6 \mathrm{~g}$ of slow-releasing fertilizer (Sierra 17-6-10 plus Minors, Scotts-Sierra Horticultural Products Co.). The pots were arranged in a randomized complete block design in the greenhouse at $24 \pm 1^{\circ} \mathrm{C}$ under ambient light. After emergence, the seedlings were thinned to one per pot. Each pot was infested with 5,000 second-stage juveniles of $H$. schachtii 45 days after sowing. Twelve weeks after infestation, the experiment was harvested as described previously.

Isolation of $\boldsymbol{H}$. schachtii cysts from soil for DNA extraction. Soil samples were air dried for 2 days at room temperature to facilitate cyst extraction. For each treatment, $25 \mathrm{~g}$ of soil from each replicate sample were pooled. Cysts were extracted from these soils according to the modified version of the cyst floatation method (23). Soil samples were put in 200-ml glass beakers. A strip of water-saturated $0.35-\mathrm{mm}$ chromatography paper was placed in the beaker so it covered the entire inside perimeter of the top third of the beaker. Water was added to the beaker until it covered half the chromatography paper. The soil mixture was stirred gently with a glass rod. One drop of Tween 20 was added to the center of the water surface, which caused the floating cysts to move toward the paper. The chromatography paper with adhering cysts was carefully removed from the beaker. Cysts were manually collected under a dissecting microscope.

DNA extraction from $\boldsymbol{H}$. schachtii cysts. Cysts were washed with sterile water by moving a cyst-water mixture in and out of a pipette tip approximately five times with three water changes. For each treatment, DNA was extracted from 20 individual $H$. schachtii

TABLE 1. Heterodera schachtii population and plant yield data in relation to various proportions of suppressive $9 \mathrm{E}$ soil $^{\mathrm{z}}$

\begin{tabular}{lccc}
\hline \% Suppressive soil & Cysts/g soil & Eggs/g soil & $\begin{array}{c}\text { Plant top } \\
\text { dry weight }(\mathrm{g})\end{array}$ \\
\hline 0 & $1.9 \mathrm{c}$ & $237.3 \mathrm{~b}$ & $63.1 \mathrm{a}$ \\
0.1 & $1.4 \mathrm{bc}$ & $180.2 \mathrm{~b}$ & $64.8 \mathrm{a}$ \\
1 & $1.0 \mathrm{ab}$ & $134.1 \mathrm{~b}$ & $64.2 \mathrm{a}$ \\
10 & $0.8 \mathrm{a}$ & $71.6 \mathrm{a}$ & $71.9 \mathrm{a}$ \\
100 & $0.8 \mathrm{a}$ & $63.5 \mathrm{a}$ & $59.4 \mathrm{a}$ \\
\hline
\end{tabular}

${ }^{\mathrm{z}}$ For each column, treatments followed by the same letter are not significantly different according to Fisher's protected least significant difference at $P=0.05$. Some of these data were also presented in an article describing bacterial rDNA associated with $H$. schachtii cysts (41). cysts according to a proteinase $\mathrm{K}$ method as previously described (28), except the cysts were crushed with a pipette tip instead of glass slides.

Analysis of fungal rDNA associated with $\boldsymbol{H}$. schachtii cysts. The fungi associated with $H$. schachtii cysts were examined by OFRG as previously described (32). PCR was used to amplify rDNA from the cysts. For each soil treatment, the PCR templates were composed of pooled DNA isolated from 20 cysts. Amplification reactions $(200-\mu \mathrm{l})$ were performed in $10-\mu$ l glass capillary tubes with a 1002 RapidCycler (Idaho Technologies, Idaho Falls,

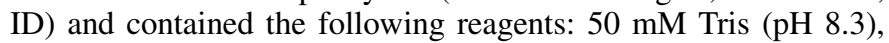
$500 \mu \mathrm{g}$ of bovine serum albumin (BSA) per ml, $2.5 \mathrm{mM} \mathrm{MgCl}_{2}$, $250 \mu \mathrm{M}$ each dNTP, $400 \mathrm{nM}$ each primer (463, TCAAGTTAGCATGGAATAATRRAATAGGA and 464, AACTCATTGCAATGCYCTATCCCCA), $20 \mu \mathrm{l}$ of DNA isolated from the cysts, and 10 units of Taq DNA polymerase. These primers are modified versions of nu-SSU-0817-5' and nu-SSU-1536-3' (5), which generate DNA fragments approximately $762 \mathrm{bp}$ in length and selectively amplify fungal small-subunit rDNA; the underlined sequence of each primer was added in a failed attempt at directionally cloning the products, and therefore, could be removed in future studies. The cycling parameters were $94^{\circ} \mathrm{C}$ for $2 \mathrm{~min} ; 35$ cycles of $94^{\circ} \mathrm{C}$ for $15 \mathrm{~s}, 56^{\circ} \mathrm{C}$ for $20 \mathrm{~s}$, and $72^{\circ} \mathrm{C}$ for $30 \mathrm{~s}$; followed by $72^{\circ} \mathrm{C}$ for $2 \mathrm{~min}$. The PCR products were gel isolated and purified with QIAquick PCR Purification Kit (Qiagen, Chatsworth, CA), ligated into pGEM-T (Promega, Madison, WI), transformed into competent Escherichia coli JM109 (Promega), and plated on Luria-Bertani agar plates containing ampicillin at $100 \mu \mathrm{g} / \mathrm{ml}$ that were surface spread with 5-bromo-4-chloro-3indolyl- $\beta$-D-galactopyranoside and isopropyl- $\beta$-D-thiogalactopyranoside. For each treatment, 301 white colonies were randomly selected for OFRG analysis. The rDNA fragments from these clones were subsequently PCR amplified, arrayed on nylon membranes, and hybridized to probes 10 nucleotides (nt) in length, using previously described protocols (32). Clones that did not hybridize to the reference probe were excluded from further analysis. Hybridization signals were used to generate fingerprints as previously described (32). The fingerprints were clustered using unweighted pair group method with arithmetic mean (UPGMA), default parameters, from the phylogenetic analysis using parsimony (PAUP) package, 4.0 beta 8 (Sinauer Associates, Inc., Sunderland, MA). Clones were identified from this analysis by their association with known rDNA sequences within the tree. This was accomplished by including fingerprints from known rDNA sequences in the UPGMA analysis and by nucleotide sequence analysis of representative clones distributed throughout the tree.

Sequence-selective PCR. Sequence-selective PCR primers were developed for the three predominant fungi identified by OFRG analysis. The primers were designed by locating DNA sequences that were conserved among small-subunit rDNA clones (at least five per group) within each fungal group using Pretty from the Genetics Computer Group (GCG) package and which had few, if any, identical matches to rDNA sequences in GenBank using BLAST (National Center for Biotechnology Information [NCBI] ) (1). The primers were D. oviparasitica-like rDNA (DactF, CAGGTCCAGACACATTA; DactR, CTTTCGGCCAAGGATT), F. oxysporum-like rDNA (FusF, GTATTGCTTTGGCAGTA; FusR, TTTCGGACAAGGAAGTA), and Lycoperdonlike rDNA (LycF, GTAATGATTAATAGGGATAGTT; LycR, CGACACATAAAAATTGAGGT). Amplification reactions $(10 \mu \mathrm{l})$ were performed in glass capillary tubes with a 1002 RapidCycler (Idaho Technologies) and contained the following reagents: $50 \mathrm{mM}$ Tris $\left(\mathrm{pH} \mathrm{8.3)}, 500 \mu \mathrm{g}\right.$ of BSA per ml, $2.5 \mathrm{mM} \mathrm{MgCl}_{2}$, $250 \mu \mathrm{M}$ each dNTP, $400 \mathrm{nM}$ each primer, $1 \mu \mathrm{l}$ of DNA isolated from the cysts, and 0.5 units of Taq DNA polymerase. The cycling parameters for the amplifications reactions containing the $D$. oviparasitica-like rDNA primers were $94^{\circ} \mathrm{C}$ for $2 \mathrm{~min} ; 35$ cycles of $94^{\circ} \mathrm{C}$ for $10 \mathrm{~s}, 60^{\circ} \mathrm{C}$ for $20 \mathrm{~s}$, and $72^{\circ} \mathrm{C}$ for $30 \mathrm{~s}$; followed by $72^{\circ} \mathrm{C}$ 
for $2 \mathrm{~min}$. The cycling parameters for the amplifications reactions containing the $F$. oxysporum-like rDNA primers were $94^{\circ} \mathrm{C}$ for $2 \mathrm{~min} ; 35$ cycles of $94^{\circ} \mathrm{C}$ for $10 \mathrm{~s}, 55^{\circ} \mathrm{C}$ for $15 \mathrm{~s}$, and $72^{\circ} \mathrm{C}$ for $20 \mathrm{~s}$; followed by $72^{\circ} \mathrm{C}$ for $2 \mathrm{~min}$. The cycling parameters for the amplifications reactions containing the Lycoperdon-like rDNA primers were $94^{\circ} \mathrm{C}$ for $2 \mathrm{~min} ; 40$ cycles of $94^{\circ} \mathrm{C}$ for $10 \mathrm{~s}, 59^{\circ} \mathrm{C}$ for $15 \mathrm{~s}$, and $72^{\circ} \mathrm{C}$ for $15 \mathrm{~s}$; followed by $72^{\circ} \mathrm{C}$ for $2 \mathrm{~min}$.

Competitive PCR. The fungal rDNA identified in this report were quantified using competitive PCR as described previously (14). Competitors were generated by low stringency PCR. These reactions contained the same components as described in the sequence-selective PCR section. For each $10-\mu$ reaction, $1 \mu \mathrm{l}$ of template DNA was used; template DNA was extracted from an avocado grove soil. The PCR parameters were $94^{\circ} \mathrm{C}$ for $2 \mathrm{~min}$; 40 cycles of $94^{\circ} \mathrm{C}$ for $10 \mathrm{~s}, 35^{\circ} \mathrm{C}$ for $2 \mathrm{~min}$, and $72^{\circ} \mathrm{C}$ for $30 \mathrm{~s}$; followed by $72^{\circ} \mathrm{C}$ for $2 \mathrm{~min}$. The amplification products were resolved on $1 \%$ agarose gels. DNA fragments approximately $100 \mathrm{bp}$ larger or smaller than the target amplicon were gel isolated and cloned into pGEM-T (Promega) to create the competitors. Quantification of the fungal rDNA from the cysts was accomplished via competitive PCR experiments, which used three to four amplification reactions containing a constant amount of DNA isolated from the cysts with a dilution series of plasmid containing the competitor sequence. Each amplification reaction was performed three times. The amplification reactions were performed as described previously. These reactions were resolved on $1.0 \%$ agarose gels and stained with ethidium bromide, and the amount of DNA in each band was enumerated by densitometry. Fungal rDNA levels were quantified by determining the competitor amount at the equivalence point in a plot of the log of competitor/cyst fungal rDNA versus log of competitor. To ensure negative PCR results were not caused by inhibitory factors in the amplification reactions, templates that did not produce a PCR product were reamplified after amending with a positive control template; in all cases, these experiments produced an amplification product (data not shown). This procedure was also performed for the sequenceselective PCR as described previously.

Sequence analysis of fungal rDNA clones. Nucleotide sequences were determined using a cycle sequencing kit (ABI PRISM BigDye Terminators, version 3.0; Applied Biosystems, Foster City, CA) and a genetic analyzer (ABI Prism 3100; Applied Biosystems) and assembled using ContigExpress (Vector NTI, Informax Inc., Frederick, MD). Sequence identities were determined using BLAST (NCBI) and AlignX (Vector NTI). To more accurately identify the three fungal rDNA sequences identified in this study, additional portions of the small subunit (SSU) gene or internal transcribed spacer (ITS) region were analyzed. These additional DNA fragments were PCR amplified from DNA isolated from the cysts, cloned, and sequenced. The ITS1, ITS2, and $5.8 \mathrm{~S}$ gene of the fungal rDNA with high sequence identity to $F$.

TABLE 2. Heterodera schachtii population data from a fumigation-induced nonsuppressive soil inoculated with cysts from soils with various levels of suppressiveness and cropped to Brassica juncea for two nematode generations $^{\mathrm{Z}}$

\begin{tabular}{lcc}
\hline $\begin{array}{l}\text { Cysts or soils transferred to } \\
\text { nonsuppressive soil }\end{array}$ & Cysts/g soil & Egg/g soil \\
\hline $\begin{array}{l}\text { Cysts from 9E soil } \\
\text { Cysts from methyl iodide-fumigated }\end{array}$ & $0.9 \mathrm{bc}$ & $40.8 \mathrm{~b}$ \\
$\quad$ 9E soil & $1.2 \mathrm{a}$ & $65.7 \mathrm{a}$ \\
$\begin{array}{l}\text { Cysts from 9E soil that were bleach- } \\
\quad \text { treated prior to transfer }\end{array}$ & $1.0 \mathrm{ab}$ & $41.3 \mathrm{~b}$ \\
9E soil (positive control) & $0.7 \mathrm{c}$ & $39.2 \mathrm{~b}$ \\
No amendment (negative control) & $1.2 \mathrm{a}$ & $63.1 \mathrm{a}$ \\
\hline
\end{tabular}

${ }^{\mathrm{z}}$ For each column, treatments followed by the same letter are not significantly different according to Fisher's protected least significant difference at $P=0.05$. Some of these data were also presented in an article describing bacterial rDNA associated with $H$. schachtii cysts (41). oxysporum and D. oviparasitica were obtained using primers ITS4 (40) and either FusF or DactF, respectively. For the organism related to Lycoperdon sp., approximately 1,016 bp of the SSU gene was obtained using primers NS1 (40) and LycR.

Nucleotide sequence data. The nucleotide sequences of the following rDNA clones identified in this work have been deposited in the GenBank database: D. oviparasitica-like rDNA, Accession nos. AY123746 to AY123757 and AY123763 (partial small-subunit) and AY185766 to AY185770 (ITS1-5.8S-ITS2); $F$. oxysporum-like rDNA, Accession nos. AY123741 to AY123745; Lycoperdon-like rDNA, Accession nos. AY123758 to 123762; and D. oviparasitica rDNA, Accession nos. AY185771 (ITS1-5.8SITS2) and AY185772 (partial small-subunit).

Data analysis for greenhouse trials. The cyst and egg data were $\log (x+1)$ transformed to normalize the data. The transformed cyst and egg data, the plant top weight data, and the competitive PCR data were subjected to analysis of variance. Fisher's least significant difference test was used to analyze the means at $P=0.05$ if treatment $F$ had a $P \leq 0.05$.

\section{RESULTS}

Greenhouse trial with five 9E soil mixtures. Treatments containing different amounts of suppressive and fumigation-induced nonsuppressive 9E soils exhibited various levels of suppressiveness (Table 1). Suppressiveness was assessed by enumerating the number of eggs and cysts per gram of soil. Fewer eggs or cysts indicated greater suppressiveness. At the termination of this trial, and two nematode generations, the $10 \%$ suppressive soil treatment contained similar numbers of eggs per gram of soil as the $100 \%$ suppressive soil treatment. Cysts per gram of soil were similar for the 1,10 , and $100 \%$ treatments. No significant differences in plant weights were observed, which is likely due to minimal plant stress resulting from optimal irrigation, fertilization, and temperature in this greenhouse trial.

Transfer of suppressiveness with $\boldsymbol{H}$. schachtii cysts. Cysts that developed in the suppressive 9E soil transferred suppressiveness to fumigation-induced nonsuppressive 9E soil (Table 2). Nonsuppressive soil amended with untreated and bleached cysts from the 9E soil had an equivalent number of eggs per gram of soil as the positive control treatment, which was a 9E soil amendment, and significantly less than the treatment amended with cysts from the fumigated $9 \mathrm{E}$ soil and the no amendment control. Nonsuppressive soil amended with cysts from the 9E soil had an equivalent number of cysts per gram of soil as the positive control treatment and significantly less than the treatment amended with cysts from the fumigated $9 \mathrm{E}$ soil and the no amendment control.

Biocidal treatments of $9 E$ soil. Three biocidal treatments were applied to the $9 \mathrm{E}$ soil to differentially alter the microbial communities and produce soils with various levels of suppressiveness. All three biocidal treatments produced soils with less suppressiveness than the untreated $9 \mathrm{E}$ soil when assessed by the number of eggs per gram of soil (Table 3). The greatest reduction in suppressiveness resulted from the methyl iodide and formaldehyde

TABLE 3. Heterodera schachtii population data from 9E suppressive soil treated with three biocidal compounds and cropped to Beta vulgaris for two nematode generations ${ }^{\mathrm{z}}$

\begin{tabular}{lcc}
\hline Soil treatment & Cyst/g soil & Eggs/g soil \\
\hline Fludioxonil & $1.6 \mathrm{a}$ & $170.4 \mathrm{~b}$ \\
Formaldehyde & $7.7 \mathrm{~b}$ & $625.2 \mathrm{c}$ \\
Methyl iodide-fumigated 9E soil & $11.0 \mathrm{~b}$ & $818.6 \mathrm{c}$ \\
Untreated 9E soil & $3.4 \mathrm{a}$ & $49.6 \mathrm{a}$ \\
\hline
\end{tabular}

${ }^{\mathrm{z}}$ For each column, treatments followed by the same letter are not significantly different according to Fisher's protected least significant difference at $P=0.05$. These data were also presented in an article describing bacterial rDNA associated with $H$. schachtii cysts (41). 
treatments. Compared with the untreated 9E soil, the fludioxonil treatment also caused a slight reduction in suppressiveness when the number of eggs per gram of soil was used as the measure of suppressiveness.

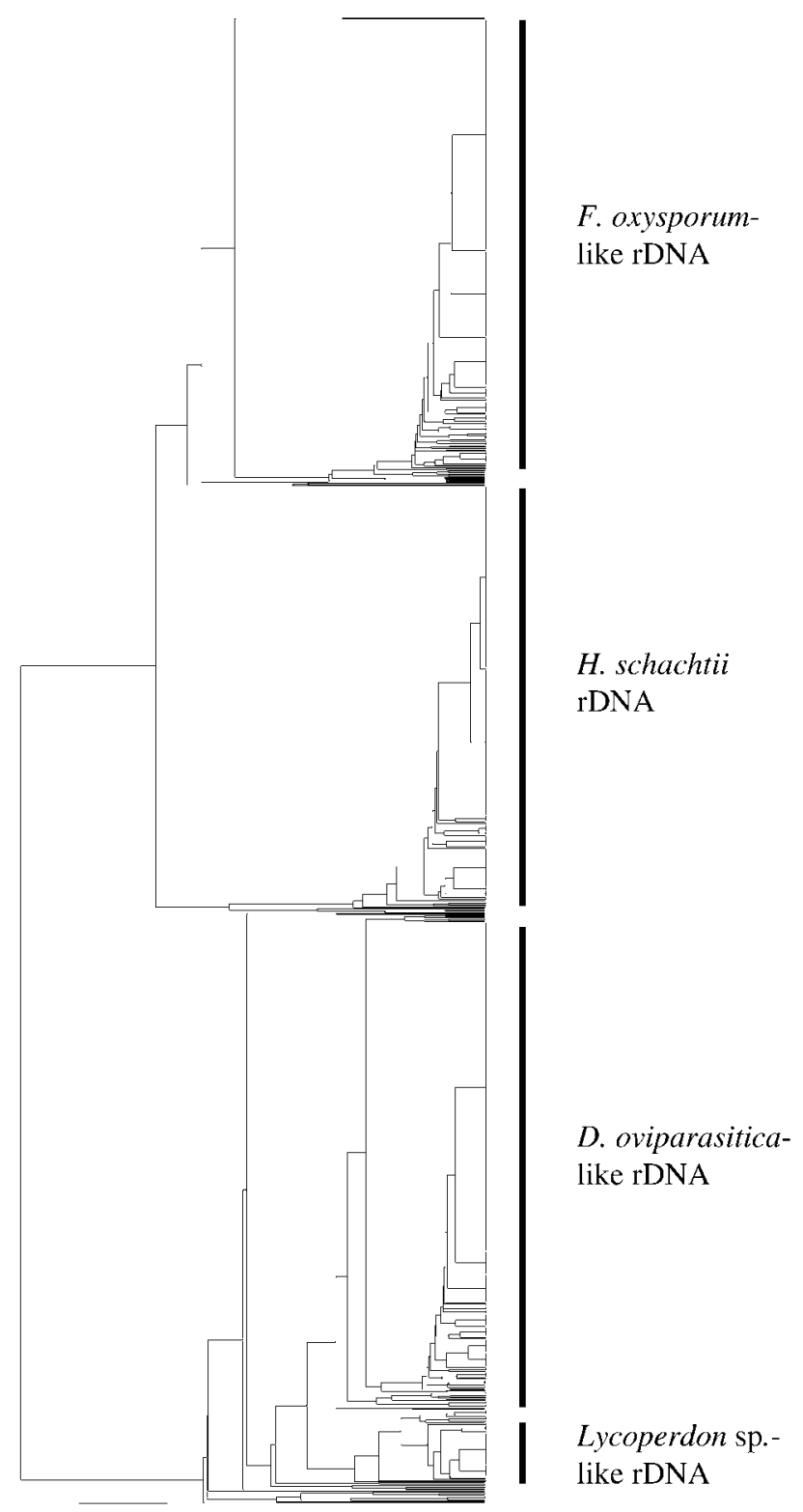

Fig. 1. Taxonomic depiction of 1,360 rDNA clones associated with Heterodera schachtii cysts that developed in soil mixtures composed of various proportions of suppressive 9E soil (Table 1). The UPGMA (unweighted pair group method with arithmetic mean) tree was constructed from rDNA hybridization fingerprints generated by oligonucleotide fingerprinting of ribosomal RNA genes analysis. The major taxonomic groups are indicated.
Analysis of fungal rDNA associated with $\boldsymbol{H}$. schachtii cysts. Fungal rDNA associated with $H$. schachtii cysts that developed in soil mixtures containing various proportions of the suppressive $9 \mathrm{E}$ soil (Table 1) were identified using OFRG (Fig. 1). Four predominant rDNA groups were identified from the 1,360 clones examined. The distribution of clone types among the soil treatments was not uniform (Table 4). Clones with high sequence identity to $F$. oxysporum were the predominant rDNA in cysts from the $1 \%$ suppressive soil treatment, though significant numbers were also found in the $0.1 \%$ treatment. Clones with high sequence identity to $D$. oviparasitica were the predominant rDNA in cysts from the 10 and $100 \%$ suppressive soil treatments. Clones with moderate sequence identity to Lycoperdon sp. were found exclusively in cysts from the $100 \%$ suppressive soil treatment. $H$. schachtii clones were the predominant rDNA in cysts from the 0 and $0.1 \%$ suppressive soil treatments; although the rDNA primers used in this study have been shown to possess specificity for fungal rDNA (4), the detection of nematode clones in the 0 and $0.1 \%$ treatments suggests that they will amplify nonfungal rDNA if fungal rDNA is scarce.

Quantification of fungal rDNA. Competitive PCR was used to quantify the amount of fungal rDNA associated with the $H$. schachtii cysts that developed in the soil mixture trial. The relative distribution of the three predominant fungi obtained by the competitive PCR experiments (Table 5) corroborated the distribution obtained by the OFRG analysis (Table 4). The levels of the D. oviparasitica-like rDNA were about 100 times greater than that of the other two fungal rDNA.

Sequence-selective PCR of $\boldsymbol{H}$. schachtii cysts. The three predominant fungi identified in the OFRG analysis (Table 4) were further examined by a sequence-selective PCR analysis of cysts from the suppressive 9E field soil and three greenhouse trials (Fig. 2). Different relative amounts of the three fungal rDNA were detected in cysts from a greenhouse trial in which 9E soils were subjected to a series of biocidal treatments. In these experiments, the $D$. oviparasitica-like rDNA was most abundant in cysts from the highly suppressive treatments, which were the fludioxonil (Fig. 2, lane 2) and nonfumigated 9E (Fig. 2, lane 5) soil treatments. For the $F$. oxysporum-like rDNA, the strongest PCR product was found in cysts from the least suppressive treatment (Fig. 2, lane 4), whereas the weakest product was found in cysts from the most suppressive treatment (Fig. 2, lane 5). The Lycoperdon-like rDNA was found only in cysts from the fludioxoniltreated soil (Fig. 2, lane 2); these primers also generated occasional spurious amplification products such as the band shown in lane 4 (Fig. 2). For all three fungi, cysts that transferred suppressiveness to nonsuppressive soil produced a stronger PCR product (Fig. 2, lane 7) than those that developed in the nonsuppressive soil and did not transfer suppressiveness (lane 6). All three fungal rDNA were also found in cysts collected from the suppressive 9E field (Fig. 2, lane 10).

Sequence analysis of fungal rDNA clones. A nucleotide sequence analysis was performed on the three predominant fungal groups identified in this study. Additional nucleotide sequences outside the region analyzed by the OFRG experiment were deter-

TABLE 4. Taxonomic distribution of rDNA clones from Heterodera schachtii cysts that developed in soil mixtures composed of various proportions of suppressive $9 \mathrm{E}$ soil ${ }^{\mathrm{Z}}$

\begin{tabular}{lccccc}
\hline \% Suppressive 9E soil & $\begin{array}{c}\text { Dactylella oviparasitica-like } \\
\text { rDNA clones }\end{array}$ & $\begin{array}{c}\text { H. schachtii } \\
\text { rDNA clones }\end{array}$ & $\begin{array}{c}\text { Fusarium oxysporum-like } \\
\text { rDNA clones }\end{array}$ & $\begin{array}{c}\text { Lycoperdon-like } \\
\text { rDNA clones }\end{array}$ & \begin{tabular}{c} 
Uncertain affiliation \\
\hline 0
\end{tabular} \\
\hline 2 & 1 & 229 & 0 & 0 & 2 \\
0.1 & 2 & 148 & 91 & 0 & 33 \\
1 & 284 & 1 & 263 & 0 & 21 \\
10 & 152 & 3 & 5 & 48 & 26 \\
100 & 7 & 31 & & 0 \\
\hline
\end{tabular}

${ }^{\mathrm{z}}$ These data were obtained by adding the number of clones in the taxonomic groups depicted in the UPGMA (unweighted pair group method with arithmetic mean) tree from the oligonucleotide fingerprinting of ribosomal RNA genes analysis (Fig. 1). 
mined. At least five clones for each fungal type were examined. The nucleotide sequences of ITS1, ITS2, and the 5.8S gene were determined for the fungus related to $F$. oxysporum. This analysis showed these sequences have 99.1 to $99.8 \%$ identity to $F$. oxysporum (Accession no. AF322076). The nucleotide sequences of ITS1, ITS2, and the 5.8S gene were determined for the fungus related to $D$. oviparasitica. This analysis showed that these sequences have 76.9 to $77.3 \%$ identity to $D$. oviparasitica. When partial small-subunit rDNA fragments from the D. oviparasiticalike organism and D. oviparasitica were compared, a 400-bp putative intron was identified in the $D$. oviparasitica sequence. When this region was removed, these two rDNA regions had 98.3 to $99.9 \%$ sequence identity. For the fungus related to Lycoperdon sp., approximately 1,016 nts of the small-subunit rRNA gene were analyzed. This analysis showed that these sequences have 96.4 to 96.9\% identity to Lycoperdon sp. (Accession no. AF026619). The relatively low sequence identity of the Lycoperdon-like rDNA to its best match in GenBank (NCBI) did not permit a confident taxonomic assignment. In fact, these sequences had similar identity levels (96.3 to $96.6 \%$ ) to rDNA from other Basidiomycetes in-

TABLE 5. Quantification of fungal rDNA associated with Heterodera schachtii cysts that developed in soil mixtures composed of various proportions of suppressive $9 \mathrm{E}$ soil ${ }^{\mathrm{x}}$

\begin{tabular}{lccc}
\hline $\begin{array}{l}\text { \% Suppressive } \\
\text { soil }\end{array}$ & $\begin{array}{c}\text { Dactylella } \\
\text { oviparasitica-like } \\
\text { rDNA clones }\end{array}$ & $\begin{array}{c}\text { Fusarium } \\
\text { oxysporum-like } \\
\text { rDNA clones }\end{array}$ & $\begin{array}{c}\text { Lycoperdon-like } \\
\text { rDNA clones }\end{array}$ \\
\hline 0 & $\mathrm{nd}^{\mathrm{z}}$ & $\mathrm{nd}$ & $\mathrm{nd}$ \\
0.1 & $\mathrm{nd}$ & $0.004 \mathrm{a}$ & $\mathrm{nd}$ \\
1 & $\mathrm{nd}$ & $0.008 \mathrm{~b}$ & $\mathrm{nd}$ \\
10 & 0.96 & $0.003 \mathrm{a}$ & $\mathrm{nd}$ \\
100 & 0.35 & $0.004 \mathrm{a}$ & 0.006 \\
\hline
\end{tabular}

${ }^{x}$ These data were obtained by measuring the amount (pg amplicon/cyst) of specific fungal rDNA associated with $H$. schachtii cysts from the soils described in Figure 1.

y Treatments with the same letter are not significantly different according to Fisher's protected least significant difference at $P=0.05$.

${ }^{\mathrm{z}}$ Not detected. cluding Lepiota procera (Accession no. L36659). A pairwise sequence analysis of the clones within the same fungal group identified minor sequence variations: $D$. oviparasitica-like rDNA $(99.2$ to $99.9 \%), F$. oxysporum-like rDNA (99.1 to $100 \%$ ), and Lycoperdon-like rDNA (99.4 to $100 \%)$. These differences could represent variation among different copies of the gene within the same organism or variation within a species or it could suggest that multiple strains or species may exist within a fungal group.

\section{DISCUSSION}

The experimental approach utilized in this project involved identifying fungi from cysts that developed in soils with various levels of suppressiveness. We theorized that we could identify the fungi involved in the $H$. schachtii suppressiveness by determining which rDNA sequences were more abundant in cysts from the highly suppressive soils than in cysts from the less suppressive soils. In greenhouse trials in which various levels of suppressiveness were produced by two different methods (Tables 1 and 3), the amount of $D$. oviparasitica-like rDNA always correlated positively with suppressiveness (Fig. 2; Tables 4 and 5), providing evidence that this organism was involved in the $H$. schachtii suppressiveness. Because the F. oxysporum- and Lycoperdon-like sequences were not consistently associated with the most suppressive soils, this suggested that they were not essential for suppressiveness. However, it is also plausible that the suppressiveness could have resulted from interactions between several organisms acting in a sequential or coordinate manner. For example, since the $F$. oxysporum-like organism is present in relatively high numbers in many of the moderately suppressive soils, it may be an initial colonizer that allows secondary organisms such as the $D$. oviparasitica-like organism to contribute to the suppressiveness. Further experimentation that examines the ability of these fungi to reproduce the suppressiveness should provide more definitive answers concerning their function in this $H$. schachtii suppressive soil.

Both D. oviparasitica and F. oxysporum have been previously associated with nematode suppressiveness. D. oviparasitica was

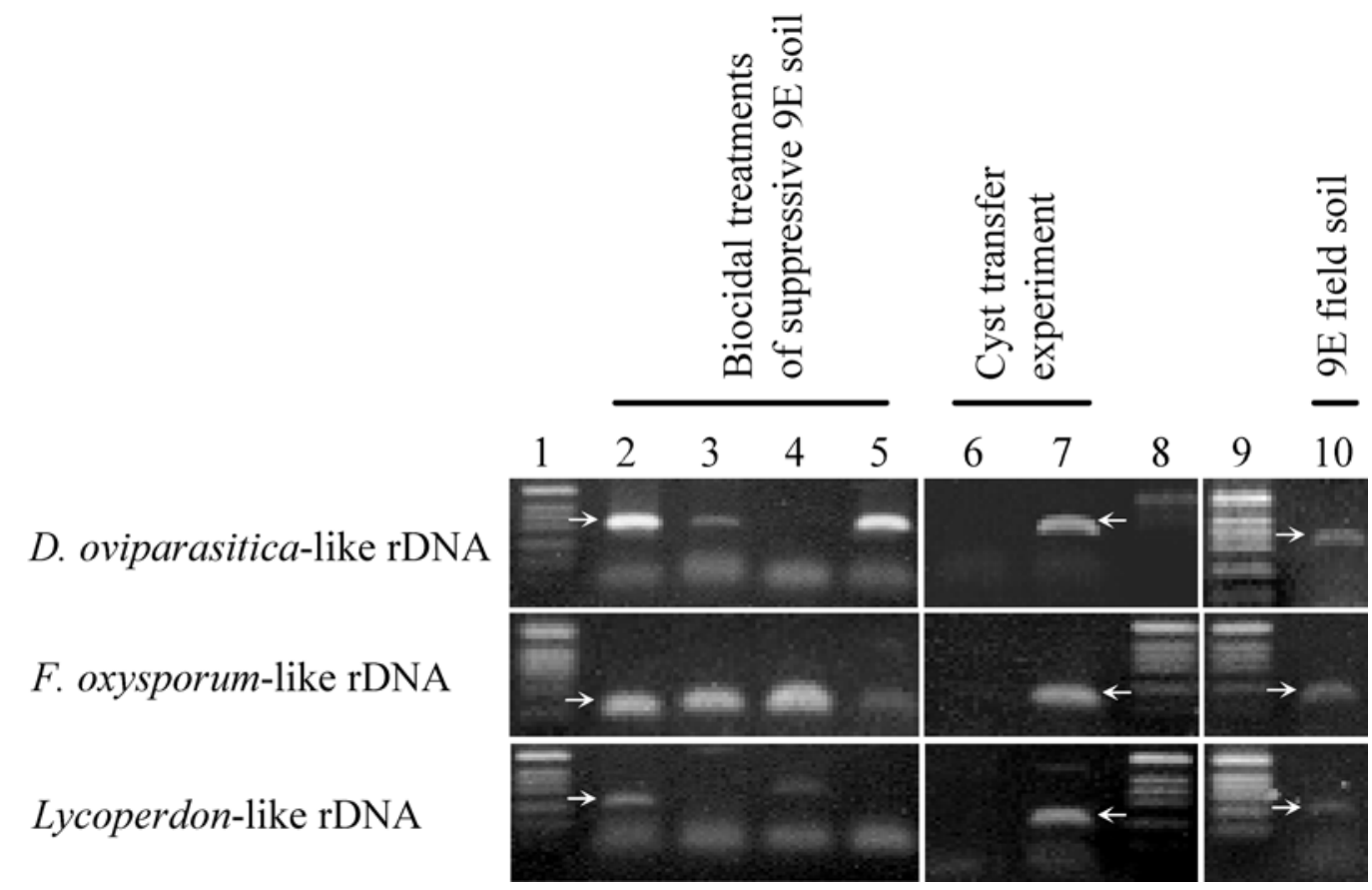

Fig. 2. Amplification of fungal rDNA associated with Heterodera schachtii cysts, using sequence-selective polymerase chain reactions (PCR). Amplification reactions were performed, using PCR primers selective for the fungal rDNA sequences identified in this study. PCR was performed on DNA from $H$. schachtii cysts derived from biocidal treatments of suppressive 9E soil (Table 2) (lanes 2 to 5), the cyst transfer experiment (Table 1) (lanes 6 and 7), and 9E field soil (lane 10). Lanes 1, 8, and 9: 1-kb DNA ladder (Invitrogen Life Technologies, Carlsbad, CA); lane 2: fludioxonil; lane 3: formaldehyde; lane 4: methyl iodide fumigation; lane 5: untreated 9E soil; lane 6: methyl iodide-fumigated 9E soil; lane 7: untreated 9E soil; and lane 10: 9E field soil. 
isolated from peach orchard soils suppressive to root-knot nematodes (25). This fungus was an effective parasite of Meloidogyne eggs that often destroyed all the eggs produced by a female (26). Introduction of $D$. oviparasitica into sterilized soil reduced root galling on peach and the second-stage juvenile population in greenhouse trials (27). Subsequent studies have shown that this fungus can also parasitize eggs from Acrobeloides sp., $H$. schachtii, and Tylenchulus semipenetrans (26). Prior studies with $F$. oxysporum have provided conflicting evidence concerning its ability to contribute to nematode suppressiveness, because it has been characterized as both a weak and strong parasite of $H$. schachtii $(9,13,15,20,31)$. Earlier studies on the suppression of the beet cyst nematode in field $9 \mathrm{E}$ found both $D$. oviparasitica and $F$. oxysporum among the most commonly isolated fungi from infested cysts (39).

Analysis of the D. oviparasitica-like sequences (partial smallsubunit rDNA) identified in this study showed that they have high sequence identity to D. oviparasitica rDNA (98.3 to $99.9 \%$ ) and slightly lower identities to Cephaliophora muscicola (Accession no. AB001108 [96.8 to 98.3\%]), Orbilia delicatula (Accession no. U72603 [96.5 to 97.8\%]), and Dactylella oxyspora (Accession no. AF106537 [96.3 to 97.8\%]). This level of relatedness to D. oviparasitica suggests that the fungus identified in this study is either a member of this species or a closely related one, and that it may be contributing to the $H$. schachtii suppression through egg parasitism or predation $(16,27)$. In addition to its affinity for cysts and eggs, $D$. oviparasitica can also be found in high levels in rhizosphere (27), and it has frequently been observed sporulating on roots (24). This close association with both the host plant and the nematode could contribute to the ability of $D$. oviparasitica to suppress $H$. schachtii populations.

The experimental design utilized in this study provides a new investigative approach for soilborne biocontrol research. This approach enables the identification of microorganisms that correlate with suppressiveness by combining OFRG, a method that permits extensive analysis of microbial community composition, with multiple techniques for producing soils with various levels of suppressiveness. Manipulating the suppressiveness in several ways allows the identification of organisms that correlate with suppressiveness over a range of conditions. This should reduce the number of organisms that need to be examined in subsequent analysis, which will likely be an important element of this investigative approach given the complexity of most soil microbial communities. After the organisms have been identified using the OFRG analysis, quantitative methods such as competitive PCR can be used to verify the important population trends. Such methods may also provide a means to determine if the rDNA sequences are artifacts such as chimeras produced by PCR (17). Attempts to culture the microorganisms can then be facilitated by utilizing a selective media based on the taxonomic classifications from the OFRG analysis. Finally, the ability of the microorganisms to reproduce the suppressiveness can be examined through greenhouse and field trials.

\section{ACKNOWLEDGMENTS}

This research was funded in part by grants from the University of California Integrated Pest Management Program and the University of California Center for Pest Management Research and Extension. L. Valinsky was supported by Vaddia-BARD Postdoctoral Award FI-306-00 from BARD, The United States-Israel Binational Agricultural Research and Development Funds. We thank J. Darsow for technical assistance and A. Scupham, E. Bent, and R. Olatinwo for critical reviews of this manuscript.

\section{LITERATURE CITED}

1. Altschul, S. F., Madden, T. L., Schaffer, A. A., Zhang, J. H., Zhang, Z., Miller, W., and Lipman, D. J. 1997. Gapped Blast and Psi-Blast-A new generation of protein database search programs. Nucleic Acids Res.
25:3389-3402.

2. Amann, R., Ludwig, W., and Schleifer, K. H. 1995. Phylogenetic identification and in situ detection of individual microbial cells without cultivation. Microbiol. Rev. 59:143-169.

3. Barns, S. M., Fundyga, R. E., Jeffries, M. W., and Pace, N. R. 1994. Remarkable archaeal diversity detected in a Yellowstone National Park hot spring environment. Proc. Natl. Acad. Sci. USA 91:1609-1613.

4. Becker, J. O., Ohr, H. D., Grech, N. M., and Sims, M. E. 1998. Evaluation of methyl iodide as a soil fumigant in container and small field plot studies. Pestic. Sci. 52:58-62.

5. Borneman, J., and Hartin, R. J. 2000. PCR primers that amplify fungal rRNA genes from environmental samples. Appl. Environ. Microbiol. 66:4356-4360.

6. Bridge, P., and Spooner, B. 2001. Soil fungi: Diversity and detection. Plant Soil 232:147-154.

7. Caswell, E. P., Thomason, I. J., and McKinney, H. E. 1985. Extraction of cysts and eggs of Heterodera schachtii from soil with an assessment of extraction efficiency. J. Nematol. 17:337-340.

8. Cook, R. J., and Baker, K. F. 1983. The Nature and Practice of Biological Control of Plant Pathogens. The American Phytopathological Society, St. Paul, MN.

9. Dackman, C., Chet, I., and Nordbring-Hertz, B. 1989. Fungal parasitism of the cyst nematode Heterodera schachtii: Infection and enzymatic activity. FEMS Microbiol. Ecol. 62:201-208.

10. Gardener, B. B. M., and Weller, D. M. 2001. Changes in populations of rhizosphere bacteria associated with take-all disease of wheat. Appl. Environ. Microbiol. 67:4414-4425.

11. Giovannoni, S. J., Britschgi, T. B., Moyer, C. L., and Field, K. G. 1990. Genetic diversity in Sargasso Sea bacterioplankton. Nature 345:60-63.

12. Hawksworth, D. L. 1991. The fungal dimension of biodiversity: Magnitude, significance, and conservation. Mycol. Res. 95:641-655.

13. Heijbroek, W. 1983. Some effects of fungal parasites on the population development of the beet cyst nematode (Heterodera schachtii $\mathrm{Schm}$.). Mededelingen Faculteit Landbouwkundige Toegepaste Biologische Wetenschappen Univ. Gent 48:433-439.

14. Jansson, J. K., and Lesser, T. 1996. Quantitative PCR of environmental samples. Pages 2.7.4.1-2.7.4.19 in: Molecular Microbial Ecology Manual. A. D. L. Akkermans, J. D. van Elsas, and F. J. de Bruijn, eds. Kluwer Academic Publishers, Dordrecht, the Netherlands.

15. Kerry, B. 1988. Fungal parasites of cyst nematodes. Agric. Ecosyst. Environ. 24:293-306.

16. Koning, G., Hamman, B., and Eicker, A. 1996. The efficacy of nematophagous fungi on predacious nematodes in soil compared with saprophagous nematodes in mushroom compost. S. Afric. J. Bot. 62:49-53.

17. Liesack, W., Weyland, H., and Stackebrandt, E. 1991. Potential risks of gene amplification by PCR as determined by $16 \mathrm{~S}$ rDNA analysis of a mixed-culture of strict barophilic bacteria. Microbiol. Ecol. 21:191-198.

18. Liu, W. T., Marsh, T. L., Cheng, H., and Forney, L. J. 1997. Characterization of microbial diversity by determining terminal restriction fragment length polymorphisms of genes encoding 16S rRNA. Appl. Environ. Microbiol. 63:4516-4522.

19. Muyzer, G., Waal, E. C. D., and Uitterlinden, A. G. 1993. Profiling of complex microbial populations by denaturing gradient gel electrophoresis analysis of polymerase chain reaction amplified genes coding for $16 \mathrm{~S}$ rRNA. Appl. Environ. Microbiol. 59:695-700.

20. Nigh, E. A., Thomason, I. J., and Van Gundy, S. D. 1980. Identification and distribution of fungal parasites of Heterodera schachtii eggs in California. Phytopathology 70:884-891.

21. Pace, N. R. 1997. A molecular view of microbial diversity and the biosphere. Science 276:734-740.

22. Reiter, B., Pfeifer, U., Schwab, H., and Sessitsch, A. 2002. Response of endophytic bacterial communities in potato plants to infection with $E r$ winia carotovora subsp. atroseptica. Appl. Environ. Microbiol. 68:22612268.

23. Shepherd, A. M. 1970. Extraction and estimation of Heterodera. Pages 23-33 in: Laboratory Methods for Work with Plant and Soil Nematodes. J. F. Southey, ed. Her Majesty's Stationery Office, London.

24. Stirling, G. R. 1979. Techniques for detecting Dactylella oviparasitica and evaluating its significance in field soils. J. Nematol. 11:99-100.

25. Stirling, G. R., and Mankau, R. 1978. Parasitism of Meloidogyne eggs by a new fungal parasite. Nematology 10:236-240.

26. Stirling, G. R., and Mankau, R. 1979. Mode of parasitism of Meloidogyne and other nematode eggs by Dactylella oviparasitica. Nematology 11:282-288.

27. Stirling, G. R., McKenry, M. V., and Mankau, R. 1979. Biological control of root-knot nematodes (Meloidogyne spp.) on peach. Phytopathology 69:806-809.

28. Subbotin, S. A., Waeyenberge, L., Molokanova, I. A., and Moens, M. 1999. Identification of Heterodera avenae group species by morphometrics and rDNA-RFLPs. Nematology 1:195-207. 
29. Tiedje, J. M. 1995. Approaches to the comprehensive evaluation of prokaryote diversity of a habitat. Pages 73-87 in: Microbial Diversity and Ecosystem Function. D. Allsopp, R. R. Colwell, and D. L. Hawksworth, eds. CAB International, Wallingford, UK.

30. Torsvik, V., Goksoyr, J., and Daae, F. L. 1990. High diversity in DNA of soil bacteria. Appl. Environ. Microbiol. 56:782-787.

31. Tribe, H. T. 1977. A parasite of white cysts of Heterodera: Caternaria Auxiliaris. Trans. Br. Mycol. Soc. 69:367-376.

32. Valinsky, L., Della Vedova, G., Jiang, T., and Borneman, J. 2002. Oligonucleotide fingerprinting of ribosomal RNA genes for analysis of fungal community composition. Appl. Environ. Microbiol. 68:5999-6004.

33. Valinsky, L., Della Vedova, G., Scupham, A. J., Alvey, S., Figueroa, A., Yin, B., Hartin, J., Chrobak, M., Crowley, D. E., Jiang, T., and Borneman, J. 2002. Analysis of bacterial community composition by oligonucleotide fingerprinting of rRNA genes. Appl. Environ. Microbiol. 68:3243-3250.

34. Vandenkoornhuyse, P., Baldauf, S. L., Leyval, C., Straczek, J., and Young, J. P. W. 2002. Evolution-Extensive fungal diversity in plant roots. Science 295:2051

35. Ward, D. M., Bateson, M. M., Weller, R., and Ruff-Roberts, A. L. 1992. Ribosomal RNA analysis of microorganisms as they occur in nature.
Adv. Microbiol. Ecol. 12:219-286.

36. Weller, D. M., Raaijmakers, J. M., McSpadden Gardener, B. B., and Thomashow, L. S. 2002. Microbial populations responsible for specific soil suppressiveness to plant pathogens. Annu. Rev. Phytopathol. 40: 309-348.

37. Westphal, A., and Becker, J. O. 1999. Biological suppression and natural population decline of Heterodera schachtii in a California field. Phytopathology 89:434-440.

38. Westphal, A., and Becker, J. O. 2000. Transfer of biological soil suppressiveness against Heterodera schachtii. Phytopathology 90:401-406.

39. Westphal, A., and Becker, J. O. 2001. Components of soil suppressiveness against Heterodera schachtii. Soil Biol. Biochem. 33:9-16.

40. White, T. J., Bruns, T., Lee, S., and Taylor, J. W. 1990. Amplification and direct sequencing of fungal ribosomal RNA genes for phylogenetics. Pages 315-322 in: PCR Protocols: A Guide to Methods and Applications. M. A. Innis, D. H. Gelfand, J. J. Sninsky, and T. J. White, eds. Academic Press, New York.

41. Yin, B., Valinsky, L., Gao, X., Becker, J. O., and Borneman, J. 2003. Bacterial rRNA genes associated with soil suppressiveness against the plant-parasitic nematode Heterodera schachtii. Appl. Environ. Microbiol. 69:1573-1580. 